\title{
Dynamics of Trusting in Translation Project Management: Leaps of Faith and Balancing Acts
}

DOI:

$10.1177 / 0891241615603449$

\section{Document Version}

Accepted author manuscript

Link to publication record in Manchester Research Explorer

\section{Citation for published version (APA):}

Olohan, M., \& Davitti, E. (2017). Dynamics of Trusting in Translation Project Management: Leaps of Faith and Balancing Acts. Journal of Contemporary Ethnography, 46(4), 391-416.

https://doi.org/10.1177/0891241615603449

\section{Published in:}

Journal of Contemporary Ethnography

\section{Citing this paper}

Please note that where the full-text provided on Manchester Research Explorer is the Author Accepted Manuscript or Proof version this may differ from the final Published version. If citing, it is advised that you check and use the publisher's definitive version.

\section{General rights}

Copyright and moral rights for the publications made accessible in the Research Explorer are retained by the authors and/or other copyright owners and it is a condition of accessing publications that users recognise and abide by the legal requirements associated with these rights.

\section{Takedown policy}

If you believe that this document breaches copyright please refer to the University of Manchester's Takedown Procedures [http://man.ac.uk/04Y6Bo] or contact uml.scholarlycommunications@manchester.ac.uk providing relevant details, so we can investigate your claim.

\section{OPEN ACCESS}




\author{
AUTHORS' POST-PRINT \\ Published in the Journal of Contemporary Ethnography, 2015, SAGE. \\ Publisher's version available at: \\ http://jce.sagepub.com/content/early/2015/10/01/0891241615603449 \\ or at https://doi.org/10.1177/0891241615603449
}

\title{
Dynamics of Trusting in Translation Project Management: Leaps of Faith and Balancing Acts
}

\author{
Maeve Olohan and Elena Davitti
}

\begin{abstract}
This paper examines the work of project managers in two UK-based translation companies. Drawing on participant observation, interviews and artefacts from field sites, our analysis focuses on the ways in which trust is developed and maintained in the relationships that project managers build, on the one hand, with the clients who commission them to undertake translation projects, and, on the other, with freelance translators who perform the translation work. The project manager's ability both to confer and to instil trust is highlighted as key to the successful operation of the company. Conceptualizing trust as a dynamic process, we consider what this process of trusting entails in this context: positive expectations vis-à-vis the other parties; willingness to expose oneself to vulnerabilities; construction of bases for suspending doubts and uncertainties (leaps of faith). We observe the important role of communication and discursive strategies in building and maintaining trust and draw conclusions for translator education.
\end{abstract}

\section{Keywords}

professional translation, translation project management, freelance translation, trust, translator education

Professional translators are engaged predominantly as freelancers by translation agencies or companies (henceforth TCs), where their work is usually managed by in-house, salaried project managers (henceforth PMs). The PM is the main and often the only point of contact for translators in their daily work and for clients who require translation, so the PM's dealings with both translators and clients are likely to be crucial to the success or failure of a TC. In this paper we examine the relations between these parties, drawing on the first phase of an ethnographic study of UK-based 
TCs and focusing on an emergent theme from our data, namely dynamic processes of trust building between PM and client and between PM and translator. With this paper we aim to contribute to a more nuanced understanding of the professional translation sector and relations between actors in the translation production network. In particular, by focusing on PMs, we gain an understanding of their coordinating role and its concomitant tensions, and we highlight the importance of trusting, as a dynamic process, in the execution of that role. We illustrate how trust is or is not conferred on and instilled in translators and clients, against a backdrop of risk and vulnerability, and we highlight the key role of communication in the trust-building process and in making the leaps of faith inherent in trusting.

\section{Research Context: Workplace Studies and Trust}

The academic discipline of translation studies considers translation from numerous scholarly perspectives, traditionally focusing much of its attention on textual production and translation strategies, or the relationship between a translation and its source text, or the cultural or literary contexts in which translations are produced and read. More recently, interest has grown in studying translators and interpreters as social agents enacting power and influence, for instance, in situations of conflict, injustice, power inequality and advocacy. Although the sociological focus on the translator, rather than solely on their texts, is a welcome development, there remain several glaring gaps in this scholarship, some of which we begin to address in this paper.

Firstly, sociological research tends, thus far, to focus on literary translators, interpreters in the justice system, or volunteer translators or interpreters; there is a dearth of empirical research on the workplaces and lived experiences of those in the professional translation sector. A small number of ethnographic studies explore professional workplaces, for example Koskinen (2008) on translation in the European Commission and Buzelin $(2006 ; 2007)$ on literary translation production in Quebec. However, these are not representative of the predominant configurations of today's translation world Abdallah (2010), Risku (2006; 2009; 2013), Ehrensberger-Dow (2014) and LeBlanc (2013) are among the few workplace-focused studies of translators and TCs in the private sector, where most translation is not of a non-literary nature. Our research adds a UK dimension to those studies conducted in Finland, Austria, Switzerland and Canada respectively.

Secondly, with a few exceptions (Rodriguez-Castro 2013; Dunne and Dunne 2011; Risku 2009; Abdallah and Koskinen 2007), translation scholars have neglected the role of the translation project manager in translation production networks. The lack of focus on the lived experiences of the diverse actors who participate in translation practices represents a significant research lacuna.

Thirdly, trust, which is the focus of this paper, has not been widely explored in translation studies. Most studies highlight the lack of trust between interlocutors who do not share a mutual linguistic or cultural understanding and who therefore require translation or interpreting to communicate (Pym 2000; 2004; Tipton 2010). In such situations, translators are perceived as spreading intercultural trust (Chesterman 1997, 183). Other scholars discuss the concept of "translational trust" (Chesterman 1997, 180) held by all parties in the translation process. "Translational trust" encompasses trust in the commissioners of the translation that the translation is worth doing, trust in the readers that the translation will be read in good faith and trust in the translator that they will 
be loyal and accountable to all parties involved, including their profession. Few studies attempt to explore empirically the dynamics of trusting in the translation workplace.

By ethnographically investigating the roles and practices of PMs in TCs, our paper addresses the lack of research on the lived experiences of actors in the translation workplace, thus contributing insights from the professional translation world that are mostly absent from academic scholarship. Furthermore, an understanding of the PM role is a crucial prerequisite for building PM components into translator training and education programmes. Finally, our study allows us to demonstrate the potential offered by ethnographic methods and workplace studies for enhancing our understanding of translation practices.

\section{Dynamics of Trust}

This paper focuses on trust because it emerged as a key theme in our data, as outlined below. A widespread acknowledgement that trust plays a central role in social cohesion and social interaction, in personal and institutional settings, has led to many models, conceptualizations and studies of trust in sociology, psychology, philosophy, economics, organizational studies and other disciplines since Simmel's seminal contribution in 1908. The publication of handbooks of trust research (Bachmann and Zaheer 2006; 2013) and the launch of the Journal of Trust Research in 2011 provide evidence of consolidation of this area of interest. Yet, the study of trust from different disciplinary perspectives has produced considerable diversity in definitions, prompting views of trust literature as complex (Lewicki, Tomlinson, and Gillespie 2006, 993) and of trust as difficult to research empirically (Misztal 1996, 95).

One of the difficulties of working on trust is that it is bound up conceptually with notions of confidence, leaps of faith, familiarity, dependence, cooperation, commitment, expectations and risk. Many approaches (Morgan and Hunt 1994) seek to model the causes and effects, or antecedents and outcomes, of trust. These models are usually based on the rational choice theory of social and economic behaviour and define trust in terms of (rational) expectations, without taking much account of affective and emotional dimensions. Some approaches (Moorman, Deshpandé, and Zaltman 1993, 82) fail to differentiate between trust and confidence or other related notions. Other definitions (Mayer, Davis, and Schoorman 1995, 712) incorporate notions of vulnerability to the actions of another party or focus on the belief that the other party will perform actions resulting in positive outcomes and will not perform unexpected actions that result in negative outcomes (Doney and Cannon 1997, 36). In some cases (Fukuyama 1995, 26), the expectations of honesty and cooperative behaviour are seen as arising in a community with shared norms. Following Lewicki et al. $(2006,1014)$, we note that, although a single accepted definition is lacking, there is some emerging consensus on the central elements of trust. Common elements can be identified as, firstly, positive expectations of cooperative behaviour by another party and, secondly, "a willingness to accept vulnerability in the relationship, under conditions of interdependence and risk" (ibid.)

Other research (Möllering 2001; Lewis and Weigert 2012) is critical of models focusing on correlations between trust and its bases or consequences, especially where these are treated as stable, measurable variables. Attempts to move away from deterministic models have led to more holistic, multidimensional and interactional approaches which are not restricted to the rational dimension but also consider affective, moral and social dimensions (Lewis and Weigert 2012), with a 
focus on trust as subjectively meaningful action in the context of specific interactions (Weber and Carter 2003, 5). Möllering's work (2013), in particular, marks a conceptual move from approaches that view trust as an attitude or a predisposition, stable over time, to approaches that conceive trust as a process. A concomitant discoursal shift from 'trust' to 'trusting' signals the dynamic and continuous nature of trust (Möllering 2013, 290).

The interpretive approach to trust, as proposed by Möllering (2001; 2005a; 2005b; 2006), is interested in the practice of trust in specific socio-cultural or socio-political contexts and in the leaps of faith', i.e. the bracketing out or suspending of uncertainties or doubt, that forms part of the trust process as people attempt to assess probabilities and act in the face of uncertainties (see also Brownlie and Howson 2005). Trust is conceptualized by Möllering (2001) as a set of three mental processes - expectation, interpretation and suspension. The outcome of the trust process is a state of favourable expectation regarding other people's actions (or unfavourable expectation in the case of distrust). Researching these three dynamic processes involves examining how people develop and maintain positive expectations when confronted with uncertainty and in situations that render them vulnerable (Möllering 2013, 288). 'Good reasons' give the trustor a basis for trust, drawing on their life-world experience (interpretation). The trustor suspends their doubt, ignorance or uncertainty, thus bracketing out the unknowable and enabling the leap of faith (suspension). The focus on uncertainties highlights the importance of risk to an understanding of trust. Trust presupposes risk, and those who trust are engaging in risk-taking behaviour, aware of the potential for negative outcomes (see also Luhmann 1988, 97-8).

Thus, in focusing on trusting by PMs we are interested in ascertaining whether the PMs hold positive or negative expectations regarding the intentions or actions of others, notably freelance translators and clients. We wish to examine specific instances of trust, focusing our attention on how PMs interpret their life-world experiences to produce 'good reasons' for trusting clients and freelance translators. In addition, we hope to explore how PMs suspend reality by identifying what constitutes the unknowable for the PMs and how they deal with the uncertainty and vulnerability stemming from that ignorance. Möllering $(2001 ; 2006)$ suggests that such insights are best achieved through reflexive, qualitative research, whose starting point is the subjective 'reality' as interpreted by the trustor, where 'good reasons' and suspension of reality are extracted, empathetically, from interpretation, not imposed on it. Our ethnographic study is aligned with this suggested approach.

In tracing the development of trust in PMs' relationships, we also draw on Lewicki and Bunker's (1996) three stages of trust in professional relationships. The first stage, "calculus trust", is partial and fragile, involving an economic, market-oriented calculation about the benefits and attendant vulnerabilities of trusting $(1996,119-120)$. Trust in business relationships often does not proceed beyond this level, and contracts and agreements may be forged to facilitate this level of trust and to discourage violations of trust. As participants interact over time (where interactions are both repeated and varied) and they develop a relationship, trust may become "knowledge-based". This level of trust is enhanced by information and predictability, and is maintained by regular communication and "courtship" (1996, 121-122). A third level, "identification-based trust", emerges when the participants identify with each other's desires and intentions and share them, to the extent that they may act for one another. Here, trustors develop an empathetic understanding of what is required to sustain the trust. 


\section{Research Settings and Methods}

As a team of two, we were able to conduct multi-sited ethnography. We focused our attention on two UK-based TCs, henceforth "Flex" and "Riva" (pseudonyms). Though different from one another, both are rather typical of configurations in the European translation sector. Riva is a small company with a workforce of three people in an open-plan office; these were the managing director (and company owner), the PM and a PM intern. Flex is also a small company, but with a larger workforce of 30 people and offices in several locations; we focused our attention on the PM activities in two Flex offices, each of which accommodated six or seven staff working in an open-plan layout.

Both companies were chosen from a listing of subscription members of the UK's Association of Translation Companies. From that directory we identified those settings in which two or more people were employed as PMs, so that we could focus our attention on the role of the PM and the relationships in the translation production network. We chose not to focus on large multinational companies, where the PM role is often disaggregated into its specialized parts (e.g. one person may be responsible for producing quotations for clients and no other activity). Our interest was in PMs who generally perform all aspects of the PM role. We also chose not to focus on companies constituted by translators working alone because translation and PM activities are embodied in a single person in those situations.

Of the small number of companies in our region fitting this profile, Riva and Flex were the most responsive to our initial approach. The gatekeepers (company owner and office manager respectively) were interested in the research and keen to collaborate, seeing the project as a useful way of developing links with the university and of having input into translator education, in which both researchers are actively involved. Through initial meetings with the gatekeepers we formalized agreements through project consent forms and the TCs' non-disclosure agreements to protect their clients' interests. Prior to observations we explained the research to employees, who had also already learnt of it from their managers, and we asked for their consent for observations and interviews, giving assurances about anonymity, confidentiality and secure data handling. All agreed to take part and remained committed to the project for its duration. Our observations comprised full days spent at each company, once, twice or three times per week over a period of twelve weeks. Observation was facilitated by open-plan configurations of the offices, though we tended to focus on one person and their work for several hours at a time and had opportunities for informal conversation about staff activities during these periods.

At Riva we focused our observations on manager Maria and PM Nicola. At Flex we observed the work of six PMs (Martina, Liz, Kate, Fiona, Mike and Anna) and office manager (Simone). Throughout the project, we shared and discussed our field notes away from the sites, reflecting on our approaches and identifying questions and themes emerging from our observations and notes. Towards the end of our observation periods we conducted semi-structured interviews to follow up on some of those key themes. At Flex we interviewed four PMs (Martina, Liz, Kate, Fiona) and Simone. At Riva we interviewed manager Maria and PM Nicola. Fiona is a newcomer to the sector but all other PMs have a minimum of two years' PM experience, and the senior managers in both companies have each worked in this area for several years. 
Our data comprises field and analytical notes from 150 hours of observation and informal conversations, artefacts (including documents stipulating policies and procedures) and the transcripts of seven interviews. Our thematic coding was recursive and both horizontal and vertical; that is, we coded for stages in the relationships and then, for each stage, we focused also on key features. We identified initiating, maintaining and terminating stages in PM relationships with both clients and translators, while relationships with translators encompassed a fourth stage prior to initiation, namely recruitment. At each stage in each set of relationships we also coded key issues, procedures and communications. Our analysis revealed that many relational features were linked to trust, which therefore emerged as a salient theme. The following sections examine more closely those dynamics of trusting.

\section{Trusting in the TC Workplace: The Pivotal PM}

Our workplace observations reveal how the PMs are pivotal in their companies' business as the sole point of contact for the client who requires a translation and the translator(s) delivering that translation. There is no direct contact between client and translator; it is through the PM's intermediation that a successful transaction takes place. While the translation supply chain may appear typical of the provision of goods and services in many domains, translation has its own peculiarities, as a "non-commodity" (Durban and Melby 2008). A tangible product is supplied to the client, the translated text, but its production requires service processes that are intangible, since the translation service is tailor-made for each client, based on the unique characteristics of the text, the purpose of the translation and the circumstances surrounding its production. The TC needs to engage a skilled translator who applies their specialist linguistic and intercultural knowledge to the task. Since the quality of the output is directly related to the quality of the client's input, the interaction between TC and client is crucial; the client may or may not know what they require, precisely, and how best to achieve it. Moreover, some clients have relatively little understanding of the processes of translation, which can lead to unrealistic expectations, especially regarding timescales and costs, and a need, expressed by our PMs, to "educate the client", to help them to identify various aspects of their potential needs. This is exemplified by Maria at Riva, who recalled how she needed to explain to a client that language varieties exist so they could clarify whether they required a translation into Portuguese or Brazilian Portuguese. At the end of the translation process, clients are often unable to make judgements on the quality of the translations since they are written in languages they do not read and understand. Their initial perception of the quality of the work may therefore centre on relational aspects of service provision by the TC.

In designing and coordinating the translation provision on behalf of the client, PMs work with the company's database of translators but personal interaction is also crucial. Once terms and conditions have been agreed with the client, the PM is responsible for assigning the job to an appropriate translator, conveying the client's needs to the translator, and doing all they can to ensure that the translator delivers a product of the required quality in the time available, at the price point enabling the TC to achieve its desirable profit margin. Finally, it may be noted that PMs are often in a similar situation to the client when it comes to judging the quality of the translation; they have strategies and techniques to undertake some quality control of the translation product but ultimately they are also unable to understand all of the languages in which translations are produced. Thus, the relationship between the translator and the PM also plays an important part in the TC's quality 
assurance. The following sections examine how the PMs confer trust on and inculcate trust in translators and clients.

\section{Trusting: PMs and Translators}

Trusting plays a major role in the assigning or non-assigning of translation work by the PMs to freelancers. Riva's and Flex's databases of freelance translators contain information about language combinations, specializations, technical competences, jobs completed and feedback on those jobs, and, in Flex's case, also outcomes of translation tests. Once a commission has been accepted from a client (see next section), the PMs need to identify suitable translators (and sometimes proofreaders) for that job. However, assigning the translation to a specific translator, which is a core aspect of the PM's activity, is seen by our PMs as entailing substantial risk; if the translator does not deliver a translation of acceptable quality by the client's deadline, there will be serious repercussions for the PM and the TC. We observed or were told about several such repercussions. These included the need to request more time from the client, or to re-assign the job, at very short notice and increased cost, thus eroding the TC's profit margin. In the worst case, the inability to fulfil the commission could result in the loss of a lucrative contract or client. Such experiences may entail financial loss but are also unwelcome because of potential damage to the TC's professional reputation and the PM's personal and professional self-esteem.

Given these risks, trust plays an important part in this stage of the translation production process. The overwhelmingly preferred option, observed among all PMs in our study, is to assign jobs to translators with whom they have worked before and who have been reliable in the past. This behaviour is a clear example of how familiarity is conducive to trusting (Luhmann 1979, 33) and of the knowledge-based trust outlined above. Past performances of translators are remembered, but also logged on the database to serve as reminders. Although a PM cannot know that any translator will complete and deliver a particular translation to the required specifications at any particular point in the future, they interpret past experiences, company records and personal contact as 'good reasons' to trust. They therefore suspend doubt and uncertainty (which may include doubt about delivering on time but also about delivering a product of a specific quality) and they assign the task, in a state of favourable expectation, seeking to define the future based on information about the past (see also Luhmann 1979, 10). It is necessary for them to take this leap of faith, since the TC could not do business if it could not commission freelance translators. Martina (Flex) sums it up: "You do have your preferred translators, and it's mainly to do with tight deadlines".

We observe also that the translator's previous work does not have to be directly experienced by the PM; on numerous occasions Flex's PMs readily assign tasks to translators with whom they have not worked before but who are recommended by other PM colleagues, based on their respective experiences. Kate (Flex) explains that "some translators are recommended to me by colleagues and if I'm happy with them I will use them again". Fiona, who is the least experienced of our PMs, has been relying almost exclusively on recommendations from her colleagues so far and describes how she is starting to form her own judgement of those translators, based on the professionalism of their communication with her and their ability to deliver jobs on time. Here PMs are using what Möllering $(2013,292)$ terms "trust histories", produced by the mental and social processes of trust and shared by actors in their communities. Moreover, they are also exhibiting trust in their fellow PMs, as colleagues. 
We can contrast the trusting of translators with whom a relationship has been formed, or about whom sufficient knowledge is available, with the lack of trust in new freelance translators. Both companies operate selection or recruitment procedures for translators, ranging from the vetting of $\mathrm{CVs}$, qualifications and prior experience to one or more stages of translation tests. Usually the addition of a translator's details to the TC's database means they have successfully completed the recruitment process. PMs are then free to assign jobs to them. However, almost unanimously our PMs express considerable reluctance to assign jobs to new additions to the database; they are patently unable to confer trust. In some instances their managers encourage the PMs to assign more jobs to new recruits, and some PMs reason that recently recruited translators are often cheaper so using them would increase their profit margin. However, even this rationalisation is not a sufficiently good reason to suspend doubt and make the leap of faith. As Liz (Flex) explains:

we're sourcing all these new translators, yet the account managers, including myself, are kind of afraid to use them. So we keep getting emails saying "please try these new people, try these new people" ... and I think we're almost hindering the process because it's so easy to go back to your favourite translators rather than email a new person.

Instead she and other PMs cite their 'good reasons' for this unfavourable expectation:

Liz (Flex): the new translators have all gone through our recruitment procedures, so they should all be reliable, trustworthy, good, good quality, good prices but we just find that that's not the case sometimes. You try one who should have who's gone through the recruitment procedure but they just don't turn out really as good as we would have hoped.

Nicola (Riva): no matter how good a CV is, you can sometimes still have a problem with someone...there is always a bit of doubt, until you use them.

Martina (Flex): we often get very tight deadlines, so unfortunately we can't afford to, personally I think I can't afford to risk, you know, delay of the project by trusting someone we have not used before ... it's how trustworthy people are in terms of meeting the deadlines... and it can be very stressful and, you know, we don't want to let the client down.

It seems that company indicators of quality, whether in the form of qualifications or test results, do not provide sufficient assurance for these PMs to suspend doubt. The PMs would require further safeguards, or other forms of information or evidence, before they could confer sufficient trust in the new recruits to commission translations from them. However, this lack of trust is largely invisible to the freelance translators. Having passed the recruitment procedures, the freelancers are informed that they have been added to the database, which they interpret as an indicator that trust is being conferred. Without an insight into these dynamics of trusting, which remain obscured to them, they fail to realise that further initiatives on their part may be necessary in order to be assigned work. Anna (Flex), for instance, comments that she expects new translators to be "proactive" in enticing PMs to try them out, for example by contacting the TC and offering their availability for short-notice or weekend jobs (Flex research notes). 
By contrast, the translators who are trusted are called on time and again, serving to reduce some of the uncertainty inherent in the commissioning of translations. This knowledge-based trust is maintained through deliberate strategies of regular communication and a form of "courtship"(Lewicki and Bunker 1996, 121-122). Simone (Flex) describes it as:

a personal relationship that you have with people that you work with over many years, and if people constantly provide you with good service and good work and ask you how your weekend has been and things like that, then you develop a relationship.

Nicola (Riva) refers to the strategy of building trust by making freelancers feel that they are in control, for example by allowing them some freedom to suggest deadlines, based on their availability, rather than always dictating deadlines to them.

Providing positive feedback on translations or communicating criticism in non-threatening and constructive ways, and paying promptly, are cited as other discursive strategies for inculcating trust and maintaining relationships. For example, Kate (Flex) recalls how a disgruntled client recently sent negative feedback that she felt was harshly formulated:

Kate says she fed it back to the translator but wasn't as harsh with the translator as the client had been in their criticism because, if she had been, the translator may have refused to take other jobs. She'd rather keep the translator on side, while alerting them to the fact that they need to take more care (Research notes, Flex).

PMs express acute awareness that good translators are in demand and actively seek to win and maintain the trust of those highly regarded translators through the image they project on behalf of themselves and their company. Liz (Flex) comments:

the good quality ones, the people who we want to use, so they really pick and choose which companies they want to work for. So if we're not treating them well, then they're not going to want to work for us.

As part of the efforts to treat translators well, we observe how all of our PMs constantly take great care to tailor their communications to individual, trusted translators, for example deciding to phone or email them depending on the translator's preference. Martina (Flex) explains that "you get to learn what people are like and you adapt to them accordingly". Riva is an established practice of sending appropriate wishes for special occasions, enquiring about health, family, holidays, recent activities, etc.:

Maria emphasizes that Nicola is very knowledgeable about their regular translators. She knows how they work, and she knows what happens in their families: birthdays, hospitalizations, maternity leaves. They exchange cards (Research notes, Riva).

The PMs usually deliberate very carefully about wording when drafting requests to translators. Fiona and Liz (Flex) comment on how their communication with translators is less formal than with clients, but "still remaining polite" (Fiona, Flex), "as if they were colleagues working in the company with us" (Liz, Flex). 
I notice how carefully Kate composes her email correspondence. She types quickly, making frequent errors but also correcting them quickly as she goes along. She can switch her Outlook settings between her two languages and does so, to allow the system to check spelling for both languages. She makes any corrections. She then reads through the email again carefully, and checks attachments by opening them, before sending the email...All emails are composed with conventional openings and closings - a very polite, professional impression made (Research notes, Flex).

The PMs expect translators to engage in similar forms of professional interaction and communication with them. For example, the PMs expect translators to be honest with them about their limitations, and this frankness is seen as an integral aspect of their trusting relationship:

Nicola explains that the translators that Riva normally use will usually say no to jobs they are not specialized in - there is a relationship of trust between them, they know each other. New people, on the other hand, do not want to say no. When it comes to their long-term translators, Nicola expects them to be honest about what they can or cannot translate, so even if they say no to a job, she would nevertheless contact them again for another assignment - she says she appreciates their honesty (Research notes, Riva).

Honest communication, if timely, is very favourably regarded by the PMs and generally does not entail detrimental consequences for the translator. This is echoed by Kate (Flex): "there are some translators who will take on anything but it's better to be honest and say if the text is not really their cup of tea". According to Martina (Flex), "a lot of bad situations in terms of the trust between the agency and the linguist can be easily avoided, you know, with good communication".

However, we also observe how the trust established can be threatened or undermined. Flex is in the process of introducing testing and ranking procedures for their long-standing translators, who may not have undergone the kind of testing to which new recruits are now subjected. The rationale for testing a proportion of long-standing translators is one of quality assurance and auditing: "to check that the people we are constantly working with are as good as we still think they are" (Simone, Flex). This is accompanied by a ranking process, based on ratings given by PMs for work undertaken, because, Simone explains, "we really do need to constantly monitor translators that we work with on a regular basis, because people do get, you know, a little bit complacent". She goes on to describe situations where translators receive work from Flex on a regular basis and the quality of their work declines, thus violating PMs' long-standing trust. For her and Flex this serves as good reason for withdrawing trust or reverting from knowledge-based trust to a level of calculus trust. Similarly, the company's database repository of information about translators' performances is used to record any negative experiences with translators and to flag this up for other PMs in the company; they are discouraged from assigning jobs to translators who have received negative feedback:

Kate (Flex): if it was, like, a really bad experience that I, like, was in trouble with the client and then I won't used them again and I might or I will also put a warning on the system for the others, so like, use with caution.

This return to cautious strategies and withdrawal of trust on the part of the TC has consequences for translators. Flex's PMs speculate in conversation that the tests and ratings being introduced for 
established translators will not be favourably received. In other cases the withdrawal of trust is not conveyed directly to the translators, but somehow has to be inferred by them, perhaps when they no longer receive regular work because they have been blacklisted on the database or negative feedback has been logged. This represents part of those dynamics which are at the core of the functioning of the translation network, but are not always made explicit.

Although our research focused on the PMs, we were able to observe aspects of the translators' trusting process. In most cases, the translator expects to receive a purchase order (PO) from the TC before commencing work on the translation; the $\mathrm{PO}$ is the material and legally binding manifestation of the TC's commitment to the translator but we noted that some PMs have a somewhat ambivalent attitude towards the PO. On the one hand, several PMs recalled problems which had arisen when translators had quoted for a job and proceeded with the work without receiving the PO but the job had, in the meantime, been assigned to another translator. On the other hand, PMs, who are busy with other things, describe the preparation of the $\mathrm{PO}$ as an administrative chore and complain about translators who expect to receive it immediately or who insist on receiving it before starting the job. From their perspective it seems that translators lack an understanding of the balancing act performed by PMs as they have to work with a budget imposed by clients and pay freelancers while still achieving a profit margin for their employer, a balancing act that Maria (Riva) describes as a "constant struggle". This lack of awareness can undermine trust relationships. The PMs feel that the translators should trust them and, more specifically, that they should trust the TC and its intention to pay and its good track record in this respect. They note that many of the regular translators will start work without the PO. Liz (Flex) outlines this situation:

I don't really get many who won't start the work without [the PO] but sometimes they do say that. Sometimes the newer people say that because they're not sure of how we work. You tend to find that the ones that know us really well know that they will get it and that we are going to pay them, we're a good, trustworthy company, we'll pay them, but obviously that PO's their guarantee and that's really important to them.

However, it is clear that the precarious economic situation of some freelancers is not conducive to trusting either the PM or the TC; for them, the informal go-ahead message is not sufficient assurance and they require the additional security of the PO before proceeding. This illustrates the fragility of calculus trust, as noted by Lewicki and Bunker (1996) above, when trust in business relationships often relies on contracts and other agreements to help avoid trust violations.

Finally, we observe that PMs empathized, to some extent, with freelance translators and the difficulties that they have in negotiating work with TCs. Nicola (Riva), for example explains, putting herself in the shoes of the freelancer, "also, you worry that you might end up working for companies you can't trust and I think everyone feels in the same boat, I think everyone wants to know who are the good companies to work for". This identification-based trust leads to PMs occasionally going to some lengths to help out translators in difficulty, for example by negotiating deadlines, as we observed Maria (Riva) do when a translator was delayed by a computer malfunction. Ongoing, regular email or telephone contact of the kind outlined above serves to develop those personal and affective dimensions of the relationship and maintain identificationbased trust. However, we observe this level of empathy relatively infrequently and we also note 
instances where PMs are unwilling to make allowances for translators' predicaments. Kate (Flex), for example, describes as "really unprofessional" the behaviour of a proofreader who was caught up in riots in Egypt and left her waiting for an urgent job without notifying her of his absence.

In summary, we note the difficulties experienced by PMs in establishing trust in new freelance translators and their frequent inability to suspend doubts relating to the likelihood that those translators can meet set deadlines but also deliver translations of a particular quality. The other side of this coin is that the PMs build trust in a set of preferred translators, drawing on their own previous experience and that of their PM colleagues. Deliberate, reflective communicative and discursive practices play an important role in the dynamic development and maintenance of this trusting. However, we also observe how this trust can be challenged and, indeed, partially or wholly withdrawn. As addressed in the next section, similarly complex dynamics characterize the relationship between PMs and clients.

\section{Trusting: PMs and Clients}

While PMs generally decide whether translators will be assigned further work or not, the power dynamics are reversed in the case of clients, as it is the clients who decide whether to assign a job to a specific TC. The establishment of a solid customer base is decisive in the success or failure of a TC and, as noted above, trust is an essential dimension of relationship building between PMs (and TCs) and clients. Trusting dynamics between them are, however, no less complex than those between TCs and freelance translators, entailing positive and negative expectations, uncertainties, risk-taking and suspension of doubts.

Trust, as a fundamental relational construct, can be seen as the "outcome of a gradual process of interaction beginning with small steps, displaying some kind of self-reinforcement and always requiring a certain level of initiative from the actors involved" (Möllering 2006, 106). We identify a number of procedures independently and systematically implemented by PMs to present their TC as professional and reliable. Such strategic moves characterize the PMs' structured, yet highly flexible approaches to initiating and reinforcing a rapport with clients and represent necessary stages in trust building.

Various of these moves are clearly aimed at customer retention and are in line with a relationship marketing approach (Baron, Conway, and Warnaby 2010); for example networking, granting discounts (either as a compensation or an acknowledgment of appreciation) or preferential rates, preparing specialized glossaries and/or keeping accounts for clients and preparing customized quotes, which can include several pages of additional information about how the TC operates and assures quality. The latter document, in particular, is perceived as crucial to project a professional image of the TC: "this is much better than previous practice - looks more professional" (Mike, Flex).

The expectation is that such actions will help to convey a trustworthy and professional image of the $\mathrm{TC}$, thus retaining and consolidating the relationship with existing clients, but also attracting new ones. Maria (Riva) explains their business approach to clients: 
We are always trying to stay on top of what's going on with the world, it's not just the position of us thinking well we've got all the clients we need, we'll just sit back and enjoy. It's not like that. ... [we are] always pushing for eh, you know, new technologies, new programs ...So I think that's a good attitude of a company. Even though we do have a big base of clients, we are always competing to keep them with us. I think there is probably a big chance of us developing even further. As you know, each relationship you build with the client brings you probably another client.

A common denominator in Flex and Riva is the crucial importance attached to communication with clients as a vector for what Maria at Riva describes as a "fruitful, long-term, trustworthy working relationship". If not planned properly and tailored to individuals, communication is perceived as a real barrier to the relationship with clients and, consequently, as undermining trust. For this reason, PMs are required to devote considerable time to writing targeted letters to clients, phrasing emails appropriately with a personal touch, taking their cue from the client's communication to them when deciding on issues such as levels of formality. Riva's staff, for instance, work with internally agreed rules on how to handle written communication, as explained in their Email Standards document:

All of our emails must display a level of professionalism, with a personal, friendly approach; all emails need to be acknowledged; always thank people for their emails.

The interactive and dynamic nature of trust building, entailing some degree of mutual monitoring, especially in its initial stages, clearly emerges from the PM's deliberate reflection on and implementation of these communication processes. Nicola (Riva), for instance, comments on the importance of getting to know clients through their written correspondence in order to communicate more effectively with them:

Depending on their response, you react accordingly ...I think that now I can sort of mirror the way that someone is talking to me ..., so that I feel comfortable.

Depending on the status of the client, i.e. prospective or long-term, communication methods may also evolve over time; the more established the relationship with the client, the more direct the communication, often conducted over the phone in an effort to make it more bespoke. As pointed out by Maria (Riva): "We tend to know most of our long-term clients directly, we speak to them over the phone and have managed to establish a relationship based on trust". Clients are also expected to keep the communication channel with TCs open in order for trust to develop. However, expectations regarding the communication of feedback can contradict this; according to Nicola (Riva), the default expectation is for clients:

to get back directly only when things are not good while they tend not to get back when things are ok, although some do ...Sometimes what it takes is the client to step back and think "uh that was something I wasn't expecting" and that's when, you know, you'll get the feedback ... Usually we get feedback if we have done something extraordinary, something that they might not think a translation company would provide. 
Given the importance of feedback for PMs (and TCs) in the relationship-building process (to monitor clients' satisfaction), alternative ways of obtaining it are sometimes put in place, e.g. by attaching a survey to the invoice. As explained by Liz (Flex) in relation to new clients:

we always call them ehm I think one to two weeks after the job is delivered and ask for their feedback and we fill in we've got a questionnaire that we fill in over the phone. If we can't get them over the phone then we send it by email, and I think were also supposed to do that periodically for existing suppliers, just to check how they're getting on with us.

Nevertheless, feedback received directly from customers seems to be perceived as more 'authentic' and, as a consequence, it is valued more than feedback elicited through other means. Nicola (Riva) comments:

Personally I prefer when we have feedback in another way ...if someone emails me with a specific comment about something specific that we have done, I prefer that because it makes me think, you know, that they went out of their way to give us good feedback, while anyone can fill out a survey.

With regard to PM's expectations towards clients, the study reveals great awareness on the part of the PMs that clients' commissioning decisions are often motivated by cost, alongside, or secondary to, a concern over quality of the translation. According to Liz (Flex), this is mainly due to a general tendency of clients to underestimate the translation process:

Clients don't know what we do. ... It's not so much the process of what we do, but the benefits of what we do for the world ... Some clients that come to us and say "just quickly translate this, it doesn't really matter". And...it does matter... So I think we need to educate clients in the business as a general...the industry as a whole.

Educating clients therefore becomes key in order to raise awareness and, consequently, enhance the client's trust in the TC, once they have assimilated the multifaceted and complex nature of the translation job.

As explained by Martina (Flex), PMs also deal with an increasing need on the part of clients to become more involved in the translation process:

they want to be more present, they want to have a bigger control over what's going on, [for example] with translation memories and reviewing the files, the client would want to review everything before it gets finalized.

While this could be perceived as evidence of a lack of trust on the part of the client, it also provides an impetus for PMs and the TCs to seek to build trust by facilitating the client's need for greater involvement. Flex, for example, begins using an online translation memory platform that allows clients to review and edit translations as they are uploaded by translators, thus enabling the client to help shape the final product, potentially reducing some of their uncertainties. 
As they do with translators, TCs employ systems to record and track business leads and clients' history with the TC. These databases include information about previous jobs, successful and unsuccessful quotes, payments, etc. Such information constitutes a track record of empirical evidence gathered through previous working experience, forming the basis for the knowledge-based trust (or distrust in cases where the relationship between clients and TC has been terminated), which characterizes the relationship with established, high-value clients. As explained by Kate (Flex), "older clients, if they work with us for a longer time, I don't think they get in touch with other agencies". Such preference displayed over time is therefore perceived as a favourable basis of trust, and this trusting rapport sometimes manifests itself in material form, such as Riva's display of the logos of their best clients on the office wall. Long-term collaboration also results in positive expectations regarding the outcomes of an enquiry performed by the specific client:

Riva has not received the go ahead from that client yet, but because it is a regular one, Nicola expects them to get back shortly, so she is planning things so as to be ready to start the following morning ... She writes it down on the central board in the office - almost as though it is an ongoing project. (Research notes, Riva)

As a dynamic construct, trust may evolve from knowledge-based to identification-based trust, when PMs attempt to identify clients' desires or needs and act to fulfil them (with a view to also gaining benefit from this). For instance, in situations where clients do not know about the use of translation memories, Kate points out that it is common practice in Flex to "explain it to clients, and they like it because it may save them money, but they don't usually want to know more than that so [we] try to keep the explanation simple". Evidence of that shift may also be seen in the efforts made by the TCs to set up facilities such as online translation request systems, to make clients' life easier (Research notes, Flex).

In the previous section we contrast the trusting of long-standing translators with the difficulty of trusting new ones. Likewise, we can contrast the trusting of clients with whom a relationship has been formed with the approach taken towards new clients, for whom little information may be available. All PMs at Riva and Flex seem to deal with the latter proactively, although also cautiously and selectively. On the one hand, when actively seeking new clients, PMs tend to adopt a strategic, bespoke approach which consists in only targeting those people who want and need their service (Research notes, Riva).

On the other hand, when approached by new clients, PMs tend to act like detectives, gathering information about the clients indirectly, by studying their online profile or using software to track the journey of sales-related emails. These actions enable PMs to make inferences which shape their expectations about the potential fruitfulness of these new contacts, despite the relative lack of information. For instance, both TCs use software to track quotation-related email correspondence with clients, gathering information on email delivery, views and forwards:

Mike looks at an email he sent recently and sees that, although there hasn't been a reply yet, it has been opened 22 times. This means that it's being passed/copied around, which is good to know (Research notes, Flex). 
In its initial stages, the relationship between PMs and clients tends to be characterized by calculusbased trust, as shown by a series of relatively formal arrangements put in place to discourage violation of trust, in the form of requirements for upfront payments, credit limitations, purchase orders, contracts and formal agreements relating to ownership of translation memory resources. The latter represents a particularly delicate terrain:

Martina explains that, although clients own their texts and the translation memory, it is preferable that they do not ask for the translation memory back as they could give it to another translation company. It's a tricky issue so not really broached if not necessary to do so. For tenders, it often has to be addressed explicitly - there can be a question about it in the application - and ownership will be set out in the contract (Research notes, Flex).

At the same time, the behaviour of new clients is closely monitored by PMs, who must also determine whether they constitute a potential new source of desirable commissions, or whether, conversely, the job may not be cost-effective and may divert resources away from other potentially more substantial jobs. Mike (Flex) explains that they decide on a case-by-case basis what to do with new clients as they don't want to be doing a lot of work if there is little chance of getting the job (Flex, research notes). To help inform their decision as to the amount of time and effort to devote to preparing a customized quote, both Riva and Flex rely on their databases containing information about tracked business leads and clients' history:

Maria does some research on the company that has requested the quote: apparently, it is a big communication company, she is pleased with it. She also finds out by looking at their folders system that they have asked for a quote before (Research notes, Riva).

As with PMs and translators, we can also identify some actions that can undermine or threaten trusting processes in the relationships between PMs and clients. For instance, clients can exert pressure on PMs in a number of different ways:

Maria and Nicola highlight the elements which add stress and pressure to daily activities, namely requests for prompt quotes (sometimes not even replied to by clients); clients adding extra words/sentences at the last minute before a project is signed off ...or even afterwards (Research notes, Riva).

Requests for quotes at short notice, at times even demanded over the phone, show clients' lack of awareness of the potentially laborious nature of quote preparation. The addition of extra words at the last minute is handled differently depending on the specific client; for instance, Maria explains that, with long-term clients they tend to do it for free even if the project has already been signed off, although she is not happy with this practice (Research notes, Riva).

Other unexpected requests from the client, for instance relating to discounts on rates or penalties for substandard quality, may set the relationship off to a bad start. An action that can lead to termination of the TC-client relationship and a complete loss of trust is clients shopping around for quotes, either openly or covertly, and then opting for the cheapest one, without necessarily 
acknowledging it. This is described by Nicola (Riva) as a "typical attitude" on the part of some clients and is a major source of annoyance for the PMs:

Nicola says this happens often, and they do not really want to work with clients who only look at costs ... they prefer to focus on the customers who value quality (Research notes, Riva).

Finally, we were able to observe some aspects of the clients' trusting process, although our focus was on PMs. The PMs' personal attitude towards clients is perceived as playing a role in encouraging clients to confer trust on the TC; PMs hold the view that they need to be calm and polite, while introversion is best avoided as it would prevent clients from knowing who they're talking to and consequently from forming a relationship with the PM (Research notes, Riva). These traits are perceived as particularly important in situations of tension or disagreement, where PMs are expected to respond constructively and non-confrontationally to clients' attacks. In one such situation, Riva's PM, Nicola, manages to diffuse a confrontation, which leads to the client being "so pleased with us that he started to pass our name on in the business and that's how our business grew with them. We became one of their preferred translation suppliers". Furthermore, despite transacting and communicating predominantly online, there is a perceived sense of trust on the part of clients towards those TCs located near them; hence the increasingly frequent decision in Riva and Flex for PMs to organize meetings with clients in person where possible, seen as a way of maximizing chances of winning and keeping the client's business. To this end, meetings are meticulously prepared:

Mike has a call to a prospective client scheduled in his diary. He prepares some handwritten notes on a pad beforehand, then makes the phone call. This is in preparation for a face-toface meeting next Monday. He will be travelling to the client's office to present the company and talk about work prospects (Research notes, Flex).

To conclude, despite PMs and TCs attempting to control as many variables as possible by implementing the moves described in this section, the relationships with clients, and new clients in particular, remain full of uncertainty for PMs and require a degree of suspension and leaps of faith. Uncertainty resides in the unpredictability of workload, of timeframes and of demands made by the client; these can cause frustration for PMs as they seek to plan their work and that of their translators. All PMs observed and interviewed cope with such difficulties on a daily basis, although, as many of them pointed out, the uncertainty is reduced as the working relationship with the client is consolidated and as mutual trust develops.

\section{Conclusion}

Abdallah and Koskinen $(2007,678)$, in one of the few other studies of trust in the translation workplace, highlight trust as the "Achilles' heel" of the translation production network because perspectives, interests and knowledge are not necessarily shared and information is not necessarily clear and legitimate for all parties, due to the long chains of actors involved. They note, moreover, that translators and clients, unless they are very powerful, may have little choice but to trust the 
translation agency, so that it is this intermediary which controls the network. Our study proceeded from that point and probed further the dynamic and interactional nature of trust-building in the TC and the specific responsibilities and actions of the PM in this regard. The PM may be seen as the locus of the TC's power, particularly from the freelance translator's perspective; PMs decide which translators are assigned jobs and may also determine the conditions under which the work is to be done, including deadlines and rates of pay. However, our analysis shows that, without trust, all parties in the translation production network would struggle to achieve their aims.

Far from having a strong sense of their own power, our PMs work hard to establish and maintain trust and they reflect on this as a burden of responsibility attendant to their role. They seem keenly aware of the vulnerability inherent in conferring trust on others and in seeking to instil others with trust in them, and they also experience the empathy accompanying identification-based trust once relationships are well established. We therefore characterize the PM role as one involving leaps of faith but also a balancing act, since they have to manage risks in both directions and they perform strategic discursive and organizational moves to build and maintain trust dynamically with both translators and clients. Many of those moves, as our analysis indicates, are deliberate and reflective.

Our analysis has shown some similarities in the way PMs handle their relationship with clients and their relationships with translators. Familiarity, although potentially conducive to knowledge-based and identification-based trust, does not necessarily ensure the duration of a long-term, trusting relationship. The fragile and volatile nature of trust becomes apparent when we consider how it is influenced by numerous variables, many of which belong to the realm of the unsaid. These include the expectations which PMs, translators and clients place on one another, and the perceptions they hold of one another. These are not always conveyed between the parties, even when things go wrong. Nevertheless, mismatched perceptions or expectations can be detrimental to the relationship and, in serious cases, can even lead to its termination.

The mode of communication adopted contributes to this state of affairs; PM-client and PMtranslator relationships can be characterized as distance-interdependent relationships (Maguire and Connaughton 2006) which are increasingly common in distributed organizations. Parties mainly interact remotely, with the PM acting as a pivot, as highlighted above. This, in turn, seems to increase the opportunities for misunderstanding or misconception, hence the need, reiterated by PMs across the data, to establish more direct contact with long-term clients and translators. Coupled with PMs' efforts to "educate" both parties, a more direct approach to the interaction seems to contribute to dispelling some of the uncertainties and to clarifying expectations, thus serving the purpose of protecting the trusting relationship over time.

As noted above, we did not design our study around trust but rather focused our attention on it as it emerged as a key theme in the analysis of PM practices and discourses. A more explicit focus on trust in research design could perhaps contribute further to this emerging understanding of trust in translation production networks. A desirable addition would be to extend the analytical focus to the translators and the clients. Although participant observation may not be realistic at the workplaces of freelance translators and clients (based anywhere in the world), a qualitative interview approach, as pursued by Möllering (2006) to explicitly address the issue of trust in relationships, might be a fruitful method of learning more about trust from those two additional perspectives. 
We conclude with a brief note about the implications of our research for translator training and education. Requisites of translator training tend to be expressed in the form of competences, and there is increasing emphasis on preparing students for employment and on reconciling the strengths of academic postgraduate education with specific but ever-changing market requirements. We believe that it is possible and desirable for translator training to prepare students for the professional world, without neglecting the intellectual and personal development fostered by academic education. We propose that this can be achieved by helping students to gain a critical, reflective, research-informed understanding of the professional world by drawing on workplace research. Research and analyses of the kind undertaken here can play a significant role in constructing an understanding of the actions and motivations of the various actors in the translation production network and in highlighting the importance of interactions and interpersonal relations, and the key role of trust in this specific social system.

\section{References}

Abdallah, Kristiina. 2010. 'Translators' Agency in Production Networks'. In Translators' Agency, edited by Tuija Kinnunen and Kaisa Koskinen, 11-46. Tampere: Tampere University Press.

Abdallah, Kristiina, and Kaisa Koskinen. 2007. 'Managing Trust: Translating and the Network Economy'. Meta 52 (4): 673-87.

Bachmann, Reinhard, and Akbar Zaheer, eds. 2006. Handbook of Trust Research. Cheltenham: Edward Elgar.

- - , eds. 2013. Handbook of Advances in Trust Research. Cheltenham: Edward Elgar Publishing.

Baker, Mona, and Gabrielle Saldanha, eds. 2008. Routledge Encyclopedia of Translation Studies. London and New York: Routledge.

Baron, Steve, Tony Conway, and Gary Warnaby. 2010. Relationship Marketing: A Consumer Experience Approach. London: Sage Publications.

Bermann, Sandra, and Catherine Porter, eds. 2014. A Companion to Translation Studies. Chichester: Wiley-Blackwell.

Brownlie, Julie, and Alexandra Howson. 2005. "'Leaps of Faith" and MMR: An Empirical Study of Trust'. Sociology 39 (2): 221-39.

Buzelin, Hélène. 2006. 'Independent Publisher in the Networks of Translation'. TTR: Traduction, Terminologie, Rédaction 19 (1): 135-73.

- - - 2007. 'Translations "in the Making".' In Constructing a Sociology of Translation, edited by Michaela Wolf and Alexandra Fukari, 135-69. Amsterdam and Philadelphia: John Benjamins.

Chesterman, Andrew. 1997. Memes of Translation. Amsterdam and Philadelphia: John Benjamins.

Doney, Patricia M., and Joseph P. Cannon. 1997. 'An Examination of the Nature of Trust in BuyerSeller Relationships'. Journal of Marketing 61 (2): 35-51.

Dunne, Keiran J., and Elena S. Dunne, eds. 2011. Translation and Localization Project Management. Amsterdam and Philadelphia: John Benjamins.

Durban, Chris, and Alan Melby. 2008. 'Translation: Buying a Non-Commodity'. http://www.iti.org.uk/attachments/category/54/Trans/ationNon-commodity.pdf Ehrensberger-Dow, Maureen. 2014. 'Challenges of Translation Process Research at the Workplace'. In Minding Translation, edited by Ricardo Muñoz Martín, 355-383. Alicante: Publicaciones de la Universidad de Alicante. 
Fukuyama, Francis. 1995. Trust: The Social Virtues and The Creation of Prosperity. New York: Free Press.

Koskinen, Kaisa. 2008. Translating Institutions: An Ethnographic Study of EU Translation. Manchester: St Jerome Publishing.

LeBlanc, Matthieu. 2013. 'Translators on Translation Memory (TM): Results of an Ethnographic Study in Three Translation Services and Agencies', Translation \& Interpreting 5(2): 1-13.

Lewicki, Roy J., and Barbara Benedict Bunker. 1996. 'Developing and Maintaining Trust in Work Relationships'. In Trust in Organizations: Frontiers of Theory and Research, edited by Roderick M. Kramer and Tom R. Tyler, 114-39. Thousand Oaks and London: Sage.

Lewicki, Roy J., Edward C. Tomlinson, and Nicole Gillespie. 2006. 'Models of Interpersonal Trust Development: Theoretical Approaches, Empirical Evidence, and Future Directions'. Journal of Management 32 (6): 991-1022.

Lewis, J. David, and Andrew J. Weigert. 2012. 'The Social Dynamics of Trust: Theoretical and Empirical Research, 1985-2012'. Social Forces 91 (1): 25-31.

Luhmann, Niklas. 1979. Trust and Power. Chichester: John Wiley \& Sons.

-- . 1988. 'Familiarity, Confidence, Trust: Problems and Alternatives'. In Trust: Making and Breaking Cooperative Relations, edited by Diego Gambetta, 94-107. London: Basil Blackwell.

Maguire, Katheryn C., and Stacey L. Connaughton. 2006. 'Relational Presence and Distanced Interdependent Relationships'. In The Ninth International Workshop on Presence (PRESENCE2006), Cleveland, $\mathrm{OH}$.

http://www.temple.edu/ispr/prev_conferences/proceedings/2006/Maguire\%20and\%20Con naughton.pdf.

Mayer, Roger C., James H. Davis, and F. David Schoorman. 1995. 'An Integrative Model of Organizational Trust'. Academy of Management Review 20 (3): 709-34.

Millán Varela, Carmen, and Francesca Bartrina, eds. 2013. The Routledge Handbook of Translation Studies. London and New York: Routledge.

Misztal, Barbara A. 1996. Trust in Modern Societies: The Search for the Bases of Social Order. Cambridge: Polity Press.

Möllering, Guido. 2001. 'The Nature of Trust: From Georg Simmel to a Theory of Expectation, Interpretation and Suspension'. Sociology 35 (2): 403-20.

- - . 2005a. 'Rational, Institutional and Active Trust: Just Do It!?'. In Trust Under Pressure: Empirical Investigations of Trust and Trust Building in Uncertain Circumstances, edited by Katinka Bijlsma-Frankema and Rosalinde Klein Woolthuis, 17-36. Cheltenham: Edward Elgar Publishing.

- - - 2005b. 'The Trust/Control Duality An Integrative Perspective on Positive Expectations of Others'. International Sociology 20 (3): 283-305.

---. 2006. Trust: Reason, Routine, Reflexivity. Kidlington: Elsevier.

- - - 2013. 'Process Views of Trusting and Crises'. In Handbook of Advances in Trust Research, edited by Reinhard Bachmann and Akbar Zaheer, 285-305. Cheltenham: Edward Elgar Publishing.

Moorman, Christine, Rohit Deshpandé, and Gerald Zaltman. 1993. 'Factors Affecting Trust in Market Research Relationships'. Journal of Marketing 57 (1): 81-101.

Morgan, Robert M., and Shelby D. Hunt. 1994. 'The Commitment-Trust Theory of Relationship Marketing'. Journal of Marketing 58 (3): 20-38. 
Pym, Anthony. 2000. 'On Cooperation'. In Intercultural Faultlines: Research Models in Translation Studies 1, edited by Maeve Olohan, 181-92. Manchester: St Jerome Publishing.

--- 2004. 'Propositions on Cross-Cultural Communication and Translation'. Target 16 (1): 1-28.

Risku, Hanna. 2006. 'Cooperation and Quality Assurance in Technical Translation Projects'. Language at Work: Bridging Theory and Practice 1 (1).

http://ojs.statsbiblioteket.dk/index.php/law/article/view/6234.

-- - 2009. Translationsmanagement: Interkulturelle Fachkommunikation im Informationszeitalter. Tübingen: Gunter Narr.

Risku, Hanna, Nicole Rossmanith, Andreas Reichelt, and Lukas Zenk. 2013. 'Translation in the Network Economy: A Follow-up Study'. In Tracks and Treks in Translation Studies: Selected Papers from the EST Congress, Leuven 2010, edited by Catherine Way, Sonia Vandepitte, Reine Meylaerts, and Magdalena Bartłomiejczyk, 29-49. John Benjamins Publishing.

Rodríguez-Castro, Mónica. 2013. 'The Project Manager and Virtual Translation Teams: Critical Factors'. Translation Spaces 2: 37-62.

Schoorman, F. David, Roger C. Mayer, and James H. Davis. 2007. 'An Integrative Model of Organizational Trust: Past, Present, and Future'. Academy of Management Review 32 (2): 344-54.

Simmel, Georg. 1908. Soziologie, Untersuchungen über die Formen der Vergesellschaftung. Berlin: Duncker \& Humblot.

Tipton, Rebecca. 2010. 'On Trust: Relationships of Trust in Interpreter-Mediated Social Work Encounters'. In Text and Context: Essays on Translation and Interpreting in Honour of Ian Mason, edited by Mona Baker, Maeve Olohan, and María Calzada Pérez, 188-208. Manchester: St Jerome Publishing.

Weber, Linda R., and Allison I. Carter. 2003. The Social Construction of Trust. New York: Kluwer Academic Publishers. 